\title{
Towards More Readable and Citable Journal
}

\author{
Jin Soo Lee, MD, PhD', Dong Joon Kim, MD², Chang-Woo Ryu, MD³
}

As members of the Korean Society of Interventional Neuroradiology, we are delighted to announce that Dr. Dae Chul Suh is now the editor-in-chief of the Neurointervention. He is one of initial members of this society and worked as the chief editorial member in its early period. As the society wishes this journal to be more impactful, he was obliged to be appointed as the Editor-in-Chief of the journal. Dr. Chang-Woo Ryu and Dr. Dong Joon Kim will assist his work as associate editors, and Dr. Jin Soo Lee will help as the chair of publication committee.

The journal, Neurointervention, has played a substantial role in reporting specific cases in the Asian-Pacific region. Valuable original articles have been reported from various countries. Based on previous works, the current editorial team will focus on publishing more expeditious and impactful scientific articles in this journal. The editorial team will try to invite more influential review articles from global experts, and will encourage neurointerventionists and neurovascular physicians to submit original articles of good quality. Our editorial board members will do the best to encourage all members and all who are dedicated to neurointervention and neurovascular diseases in participating to make our journal more readable and citable. In addition, the journal will have a role as a forum of discussion by posting various types of articles.

Lastly, we should express our gratitude to all interna- tional editorial board members, reviewers and especially Dr. Woong Yoon, the immediate past chief editor. They all have made their best efforts to improve the journal quality despite their hectic schedules. Based on their extraordinary commitment and passion, we will continue to make this journal more informative and impactful. We hope that you have more interests in the Neurointervention. Thank you.

'Department of Neurology, Ajou University School of Medicine and Hospital, Suwon, Korea

2Department of Radiology, Yonsei University College of Medicine, Seoul, Korea

${ }^{3}$ Department of Radiology, Kyung Hee University Hospital at Gangdong, Seoul, Korea

Correspondence to: Jin Soo Lee, MD, PhD

Department of Neurology, Ajou University School of Medicine, Worldcup-ro 164, Yeongtong-gu, Suwon, Gyunggi-do 16499, Korea

Tel. 82.31.219.5175 Fax.82.31.219.5178 E-mail: jinsoo22@gmail.com

This is an Open Access article distributed under the terms of the Creative Commons Attribution Non-Commercial License (http://creativecommons.org/licenses/by-nc/3.0) which permits unrestricted non-commercial use, distribution, and reproduction in any medium, provided the original work is properly cited. 